\title{
Rational Construction of Mitochondrial Targeting, Fluorescent Self-Reporting Drug-Delivery Platform for Combined Enhancement of Endogenous ROS Responsiveness
}

Jun Li ${ }^{a}$, Yun-Jie Wei ${ }^{a}$, Xian-Ling Yang ${ }^{a}$, Wan-Xia Wu ${ }^{b}$, Meng-Qian Zhang ${ }^{a}$, Meng-Yang Li ${ }^{a}$

Zu-E Hu ${ }^{a}$, Yan-Hong Liu ${ }^{a}, N a W^{*}{ }^{* a}$ and Xiao-Qi Yu*a

${ }^{a}$ Key Laboratory of Green Chemistry and Technology (Ministry of Education), College of Chemistry, Sichuan University, Chengdu, 610064, China.

${ }^{b}$ College of Pharmacy and Biological Engineering, Chengdu University, Chengdu 610106, P. R. China

*Corresponding authors: wnchem@scu.edu.cn (N. Wang); xqyu@scu.edu.cn (X.-Q. Yu); Fax:

$+86-28-85415886$ 
1. Followed by the similar facile synthesis we combined as before ${ }^{1,2}$.

$$
\text { (C) }
$$

Scheme S1. Synthesis of $N$-propargyldiethanolamine, $\mathrm{mPEG}_{1000}-\mathrm{OH}\left(\mathrm{N}_{3}\right)$ and $\mathrm{mPEG}_{2000^{-}}$ $\mathrm{OH}\left(\mathrm{N}_{3}\right)$.

\section{Synthesis of ABBO.}<smiles>Nc1ccccc1O</smiles><smiles>Nc1ccc(O)c(C(=O)O)c1</smiles><smiles>Nc1ccc(O)c(-c2nc3ccccc3o2)c1</smiles><smiles>Nc1ccc(O)c(-c2nc3ccccc3o2)c1</smiles><smiles>[N+]=[N+]=[N-]</smiles>

1<smiles>Nc1ccc(O)c(-c2nc3ccccc3o2)c1</smiles>

AHBO

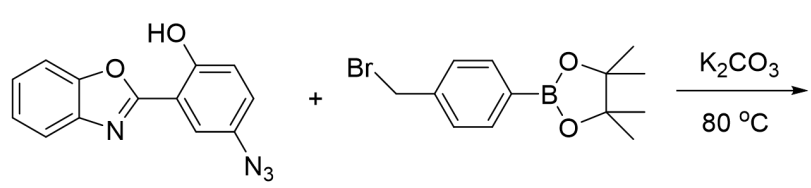

AHBO

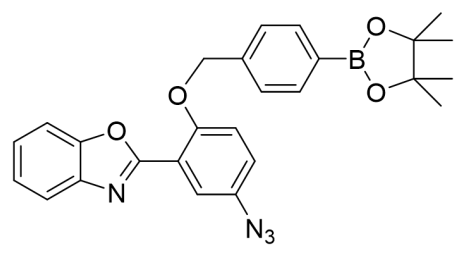

ABBO

Scheme S2. Synthesis of ABBO.

Compound $\mathbf{1}$ and AHBO was synthesized according to literature ${ }^{3}$ in the same method. A mixture of AHBO (0.5 mmol), 4-(bromomethyl)benzene boronic acid pinacol ester (0.6 mmol), and $\mathrm{K}_{2} \mathrm{CO}_{3}(1.5 \mathrm{mmol})$ in dry $10 \mathrm{~mL}$ DMF was heated at $80{ }^{\circ} \mathrm{C}$ for $20 \mathrm{~h}$. After cooling, the 
mixture was filtered. Then cold water $(50 \mathrm{~mL})$ was added to the mixture and extracted with EA $(100 \mathrm{~mL} \times 3)$. The organic layers were combined, washed with water $(100 \mathrm{~mL} \times 3)$ and brine $(100 \mathrm{~mL} \times 3)$, and dried with $\mathrm{Na}_{2} \mathrm{SO}_{4}$. The solvents were evaporated to obtained crude product, which was purified by silica chromatography $(\mathrm{DCM} / \mathrm{EA}=100: 10 \mathrm{v} / \mathrm{v})$ to give the $\mathrm{ABBO}$ as brown solid (38\% yield).

\section{Synthesis of PSP.}

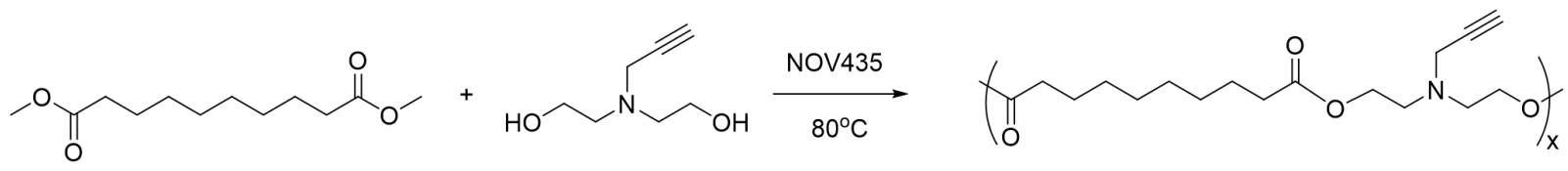

Scheme S3. Synthesis of PSP.

PSP was synthesized by a method described previously. ${ }^{4}$ The monomers N-propargyldiethanolamine $(10 \mathrm{mmol})$ and dimethyl 3,3'-dithiopropionate (15 mmol) were transferred into a Schlenk tube. Diphenyl ether $(200 \mathrm{wt} \%$ vs. total monomer $)$ and Novozym-435 (10 wt $\%$ vs. total monomer) was added to the mixture, respectively. The reaction was maintained at $80{ }^{\circ} \mathrm{C}$ under low pressure. The enzyme was removed by filtration after $48 \mathrm{~h}$, and the filtrate was washed by $50 \mathrm{~mL}$ hexane for three times. Subsequently, the filtrate was precipitated three times using a mixture of hexane and chloroform $(3: 1, \mathrm{v} / \mathrm{v})$. The products were dried under vacuum, and resulting in a yellow sticky liquid in $84 \%$ yield. 
Table S1. The content of mPEG, ABBO and TPP unit of the polymeric nanocarriers.

\begin{tabular}{|c|c|c|c|}
\hline Sample & $\begin{array}{c}f_{\mathrm{w}, \text { mPEG unit }}{ }^{\mathrm{a}} \\
(\%)\end{array}$ & $\begin{array}{c}f_{\mathrm{w}, \mathrm{ABBO}} \text { unit }^{\mathrm{b}} \\
(\%)\end{array}$ & $\begin{array}{c}f_{\mathrm{w},} \text { TPP unit }{ }^{\mathrm{c}} \\
(\%)\end{array}$ \\
\hline $1 \mathrm{~K}-\mathrm{OH}$ & 39.1 & 27.2 & - \\
\hline $2 \mathrm{~K}-\mathrm{OH}$ & 57.8 & 18.7 & - \\
\hline 1K-TPP & 33.9 & 23.7 & 13.1 \\
\hline 2K-TPP & 51.7 & 16.7 & 10.5 \\
\hline
\end{tabular}

Table S2. GPC characterization data of the polymeric nanocarriers.

\begin{tabular}{ccccc} 
Sample & Mn (Da) & Mw (Da) & Mp (Da) & PDI \\
\hline PSP & 7000 & 9400 & 8900 & 1.34 \\
$\mathbf{1 K - O H}$ & 10200 & 12600 & 12500 & 1.23 \\
$\mathbf{1 K - T P P}$ & 12900 & 19700 & 17700 & 1.32 \\
$\mathbf{2 K - O H}$ & 14200 & 17000 & 17500 & 1.20 \\
$\mathbf{2 K - T P P}$ & 21000 & 26500 & 24200 & 1.26 \\
\hline
\end{tabular}


Table S3. Basic characteristics of the polymeric micelles.

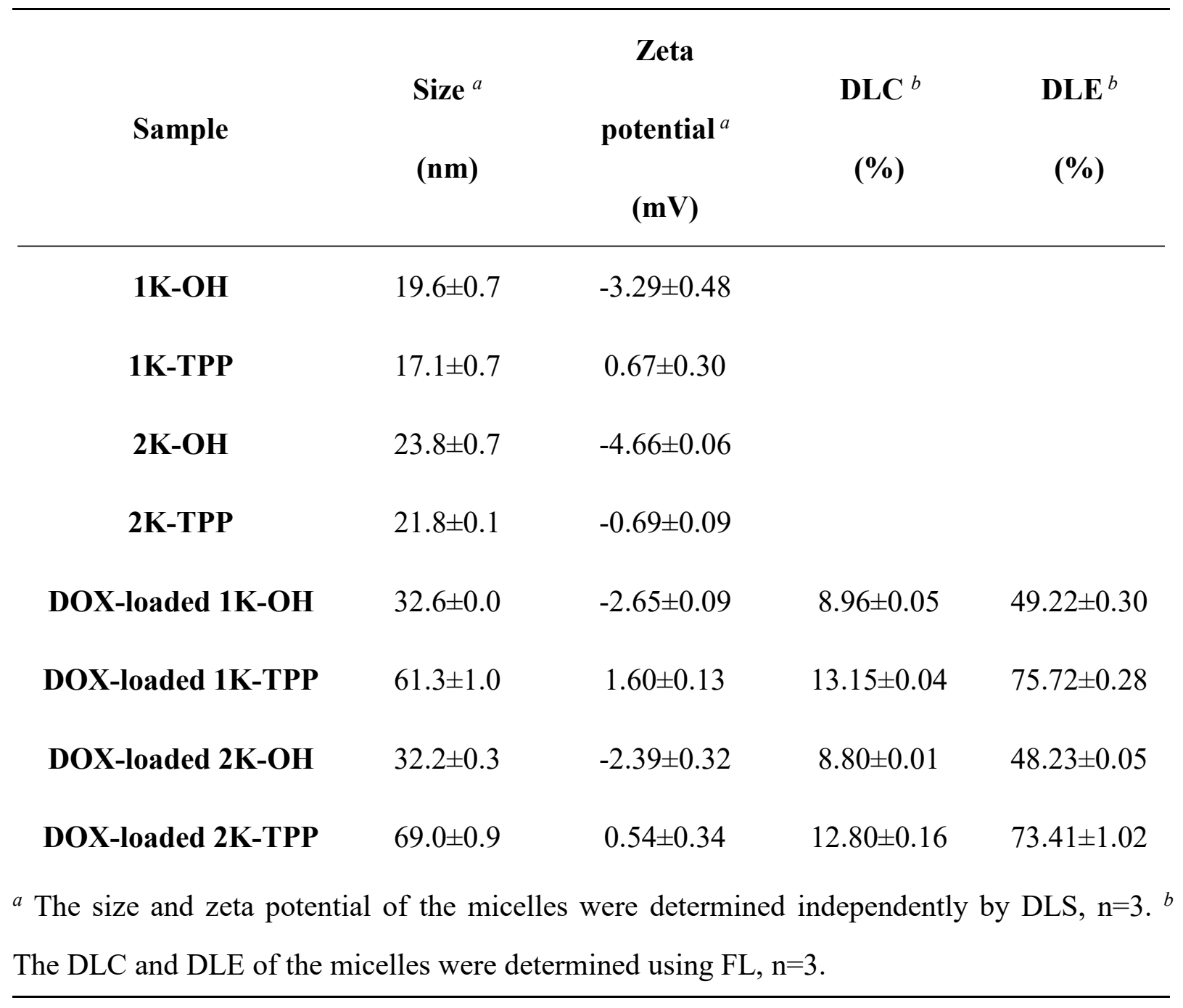




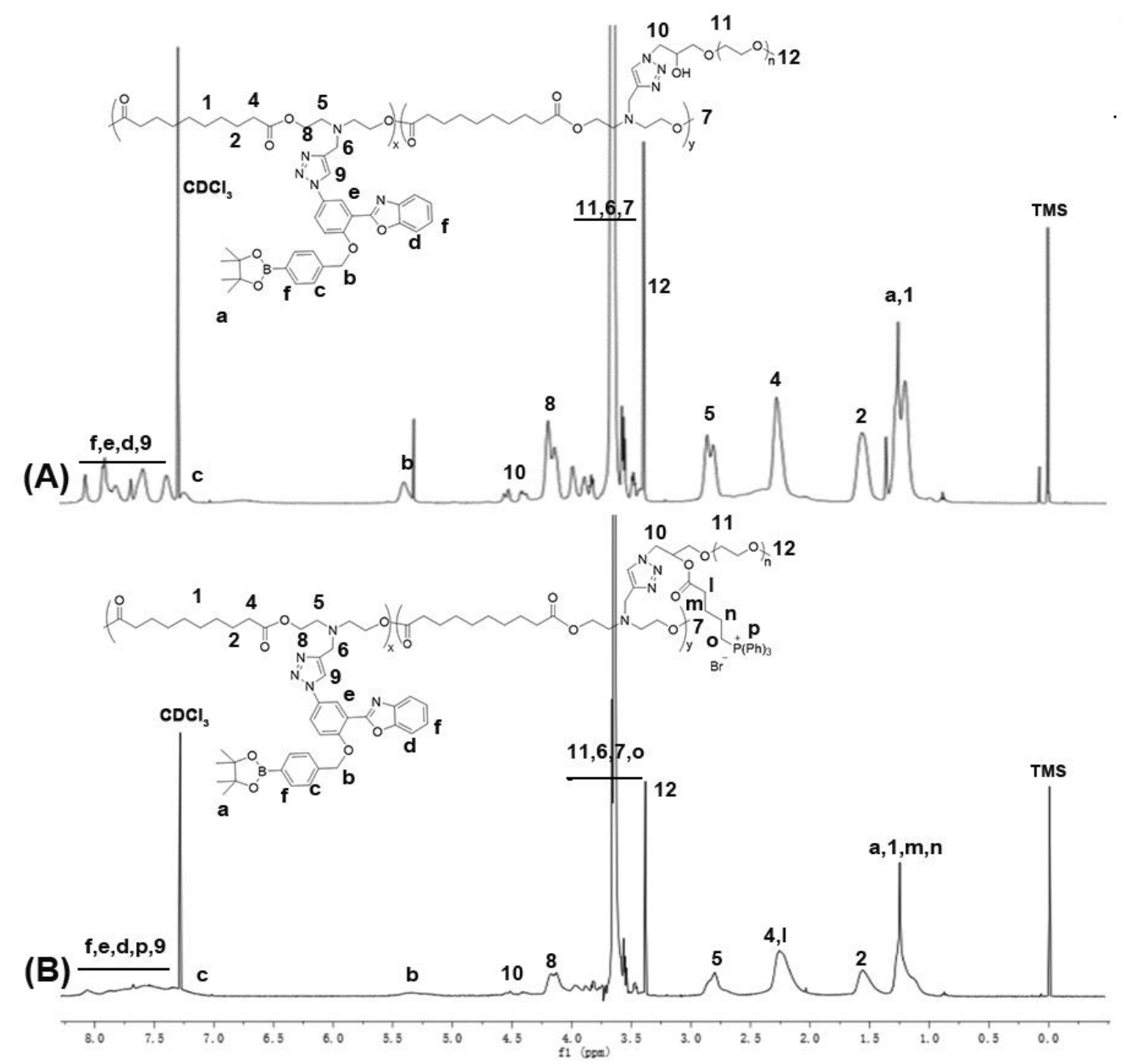

Figure S1. ${ }^{1} \mathrm{H}$ NMR spectra of (A) $\mathbf{2} \mathbf{K}-\mathbf{O H}$ and (B) 2K-TPP in $\mathrm{CDCl}_{3}$.

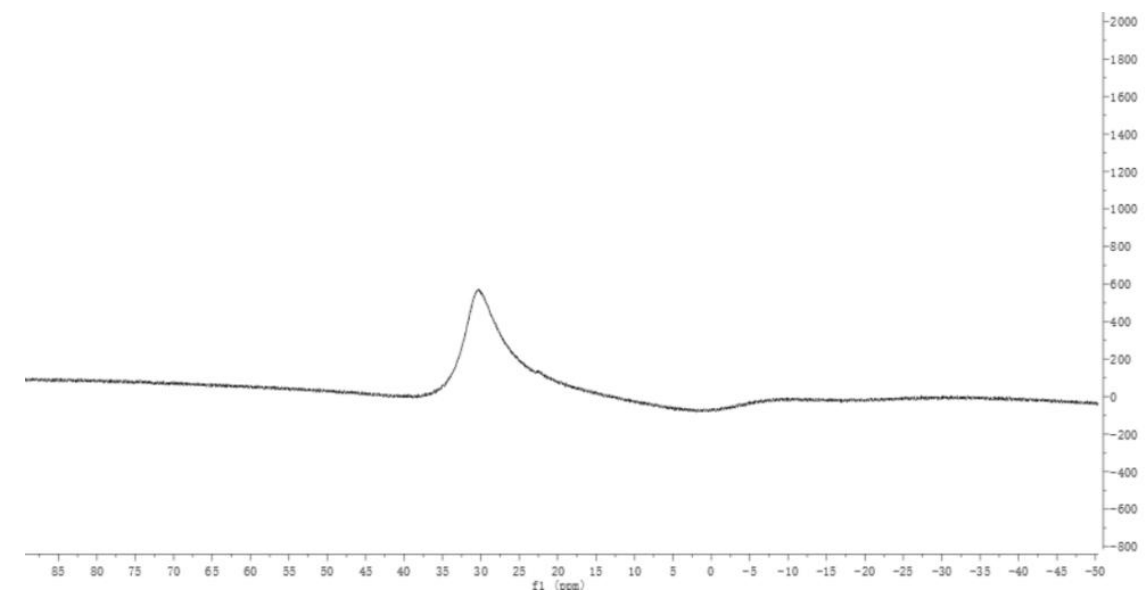

Figure S2. ${ }^{11} \mathrm{~B}$ NMR spectra of $\mathbf{1 K}-\mathbf{T P P}$ in $\mathrm{CDCl}_{3}$. 


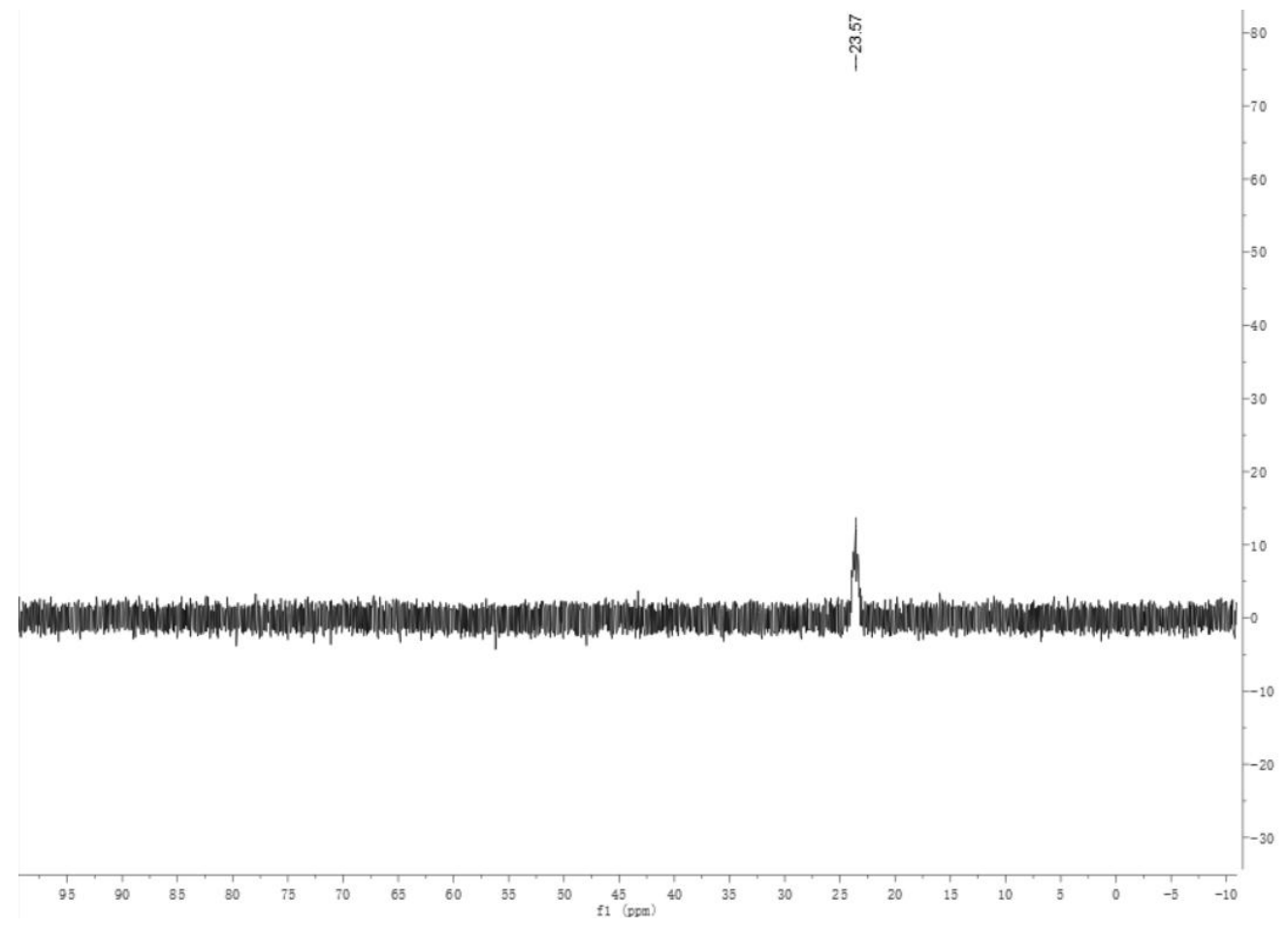

Figure S3. ${ }^{31} \mathrm{P}$ NMR spectra of $1 \mathrm{~K}-\mathrm{TPP}$ in $\mathrm{CDCl}_{3}$.

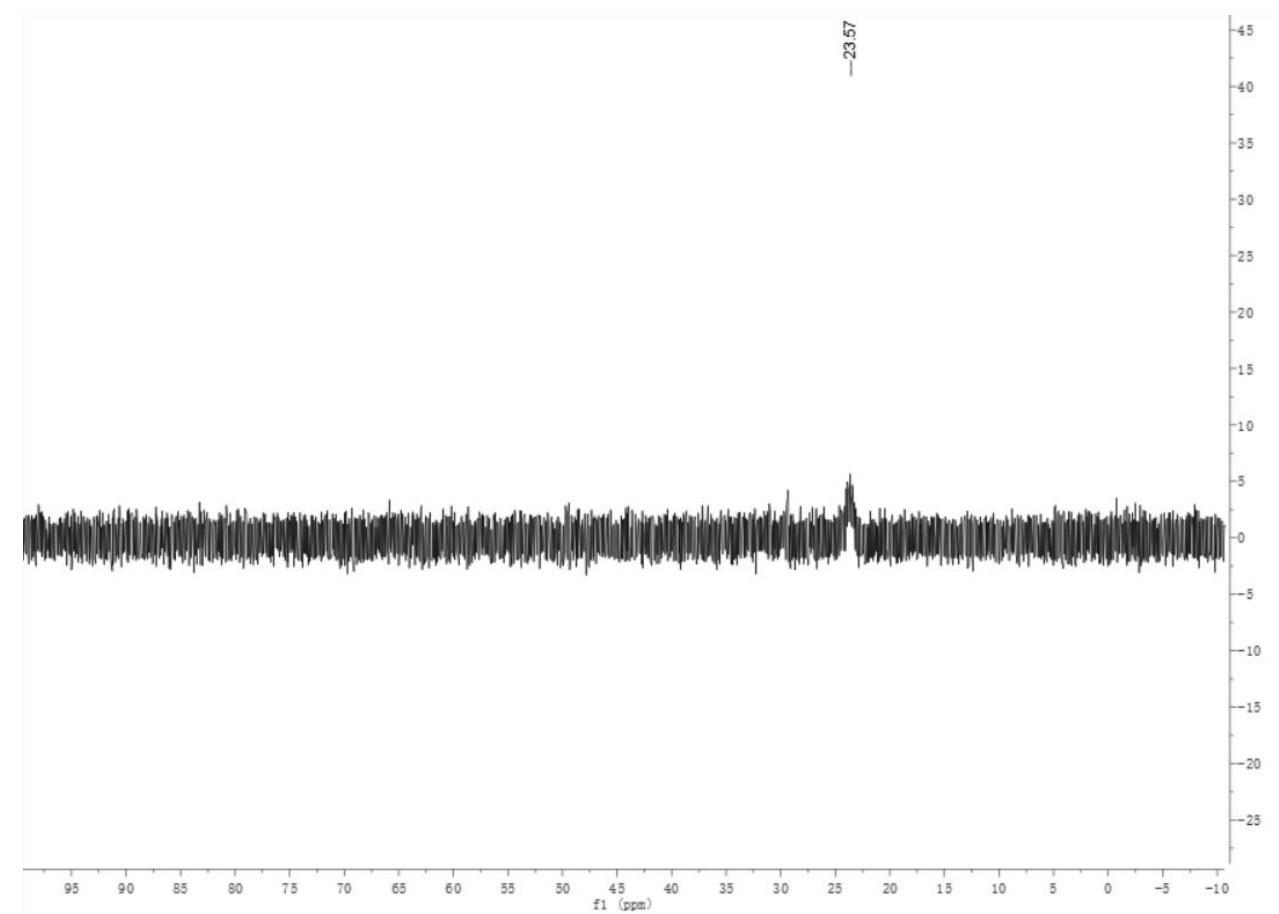

Figure S4. ${ }^{31} \mathrm{P}$ NMR spectra of $\mathbf{2 K}-\mathbf{T P P}$ in $\mathrm{CDCl}_{3}$. 
(A)

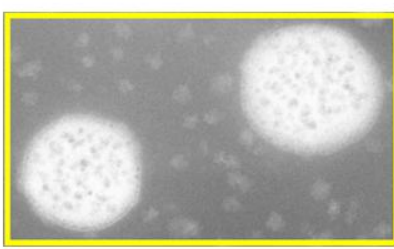

(B)

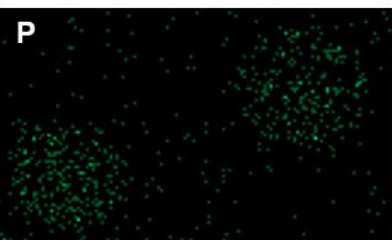

o

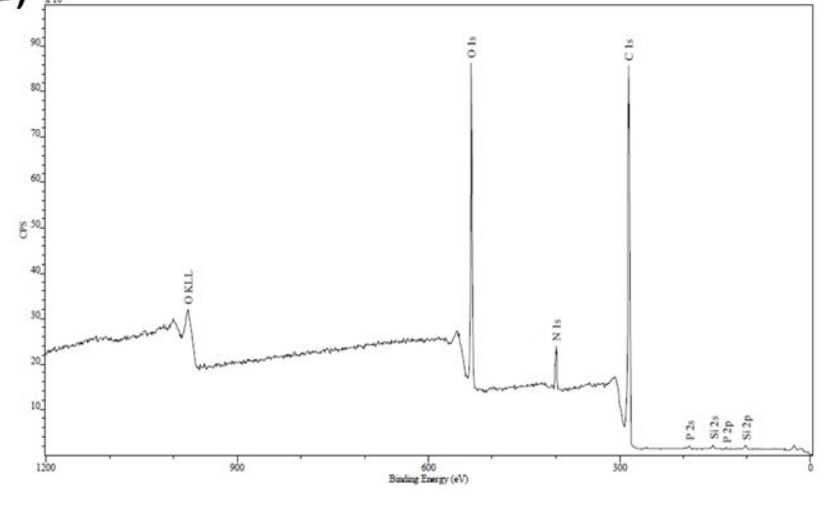

Figure S5. Mapping image (A) and XPS (B) of blank 1K-TPP.

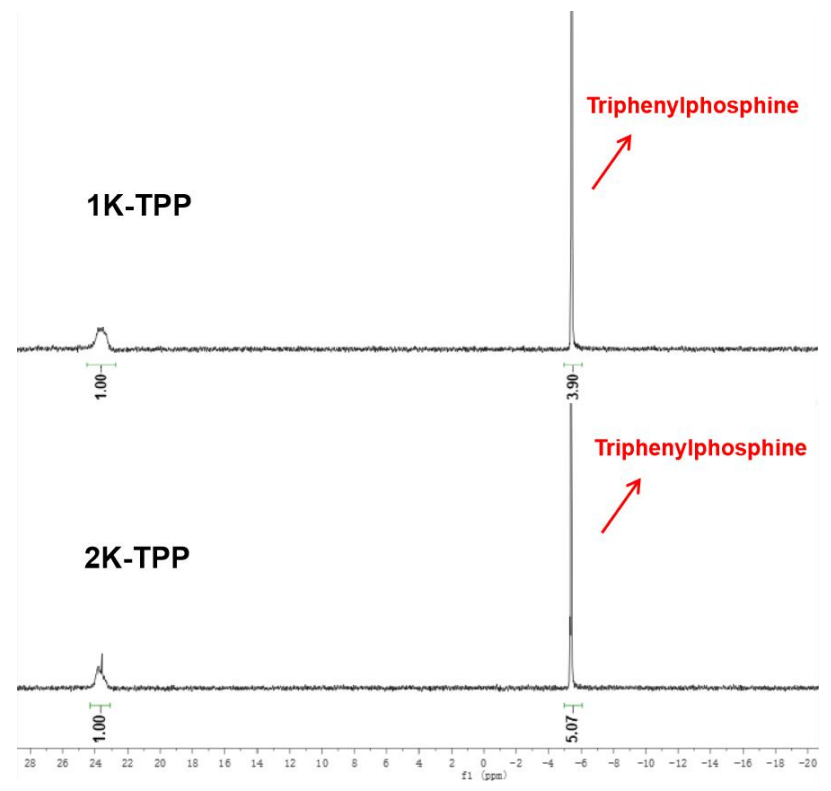

Figure S6. ${ }^{31} \mathrm{P}$ NMR spectra of 1K-OH, 2K-OH, 1K-TPP and 2K-TPP in $\mathrm{CDCl}_{3}$. 


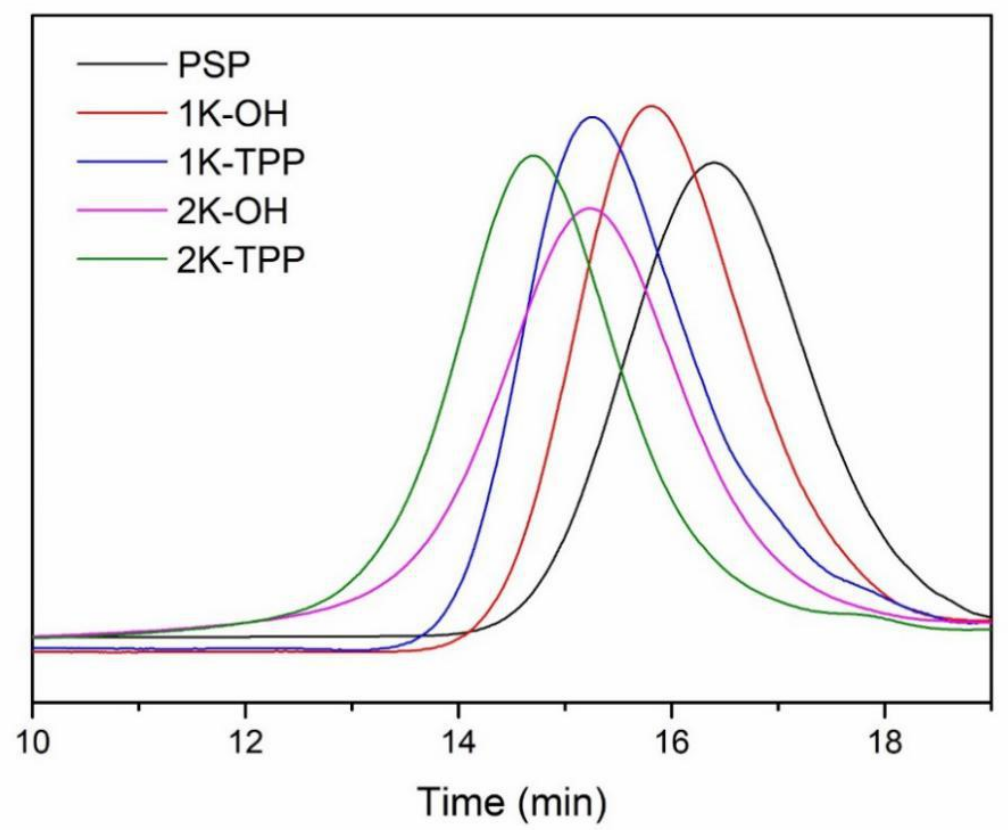

Figure S7. GPC traces of PSP, 1K-OH, 1K-TPP, 2K-OH and 2K-TPP.

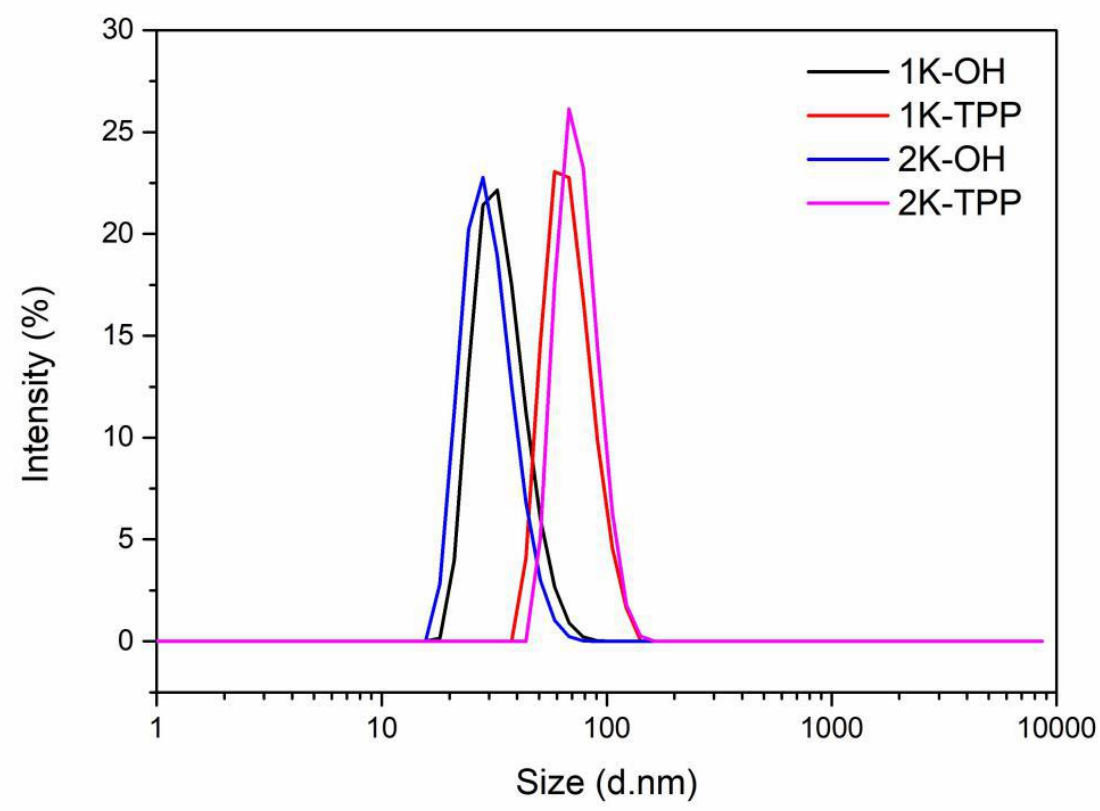

Figure S8. Size of DOX-loaded 1K-OH, 1K-TPP, 2K-OH and 2K-TPP. 


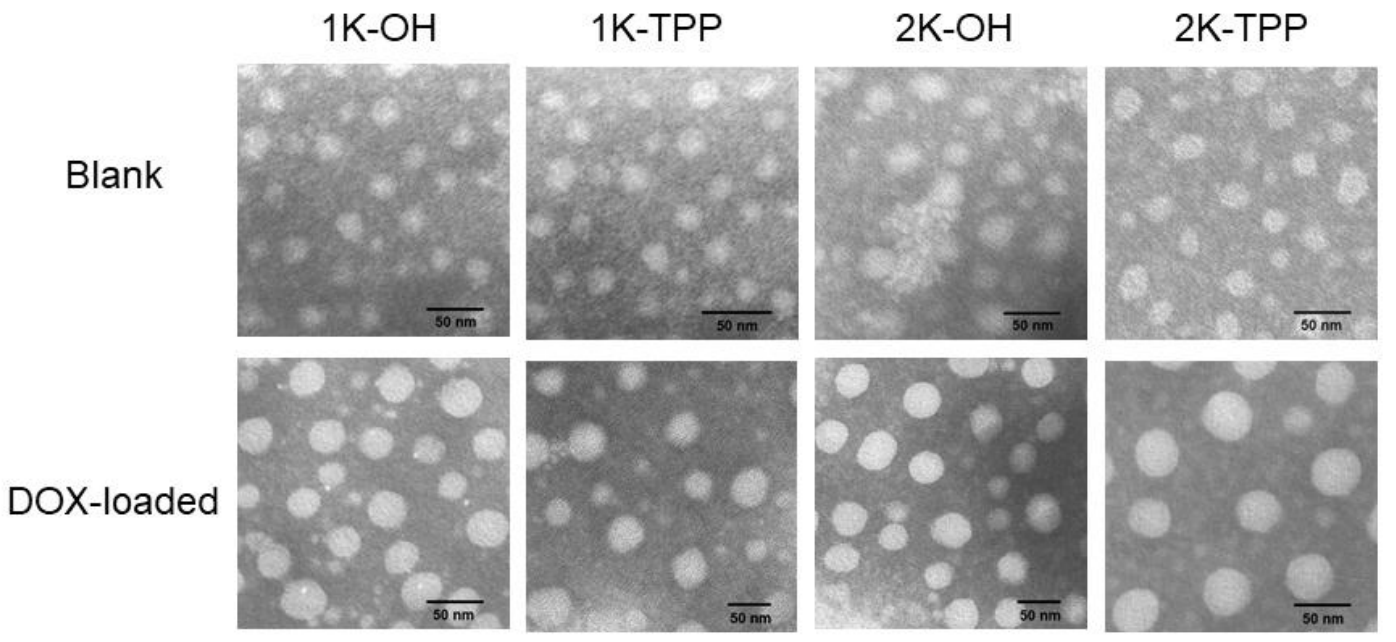

Figure S9. TEM micrographs of blank and DOX-loaded 1K-OH, 1K-TPP, 2K-OH and 2K-TPP. Scale bar $=50 \mathrm{~nm}$.

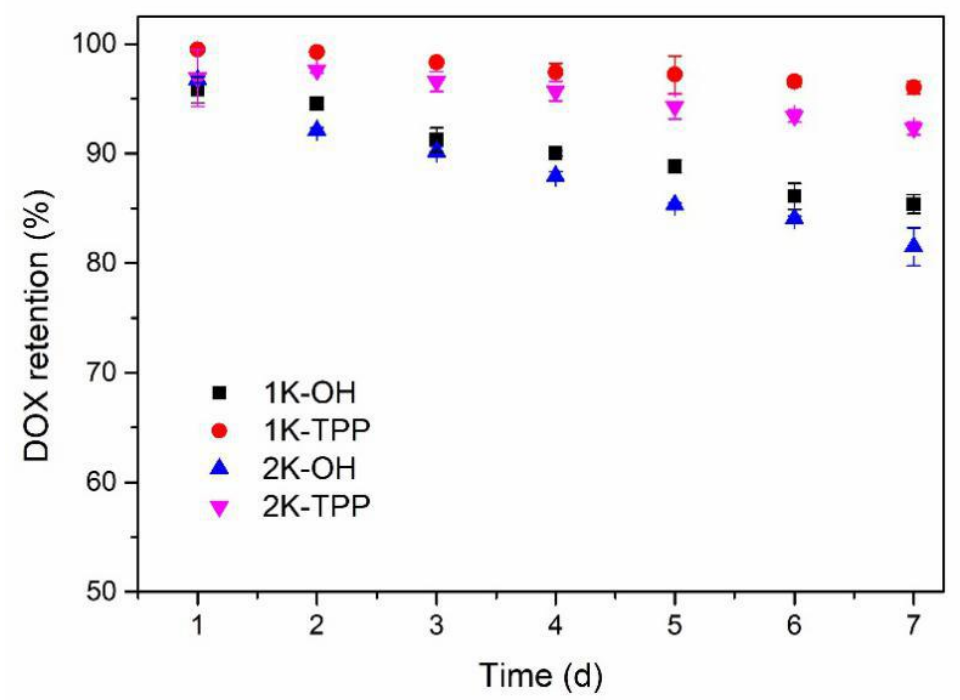

Figure S10. Storage stability of DOX-loaded 1K-OH, 1K-TPP, 2K-OH and 2K-TPP were stored at $4{ }^{\circ} \mathrm{C}$ for 7 days. 


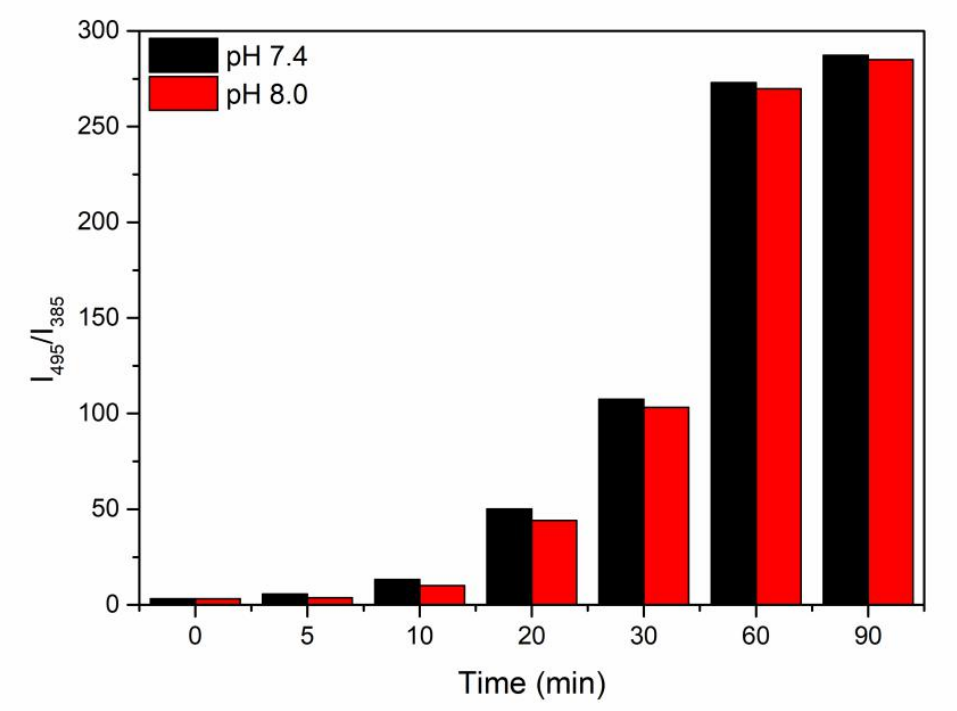

Figure S11. Plots of $\mathrm{I}_{495} / \mathrm{I}_{385}$ under $\mathrm{pH} 7.4$ or $\mathrm{pH} 8.0$ with $1 \mathrm{mM} \mathrm{H}_{2} \mathrm{O}_{2}$ of 1K-TPP.
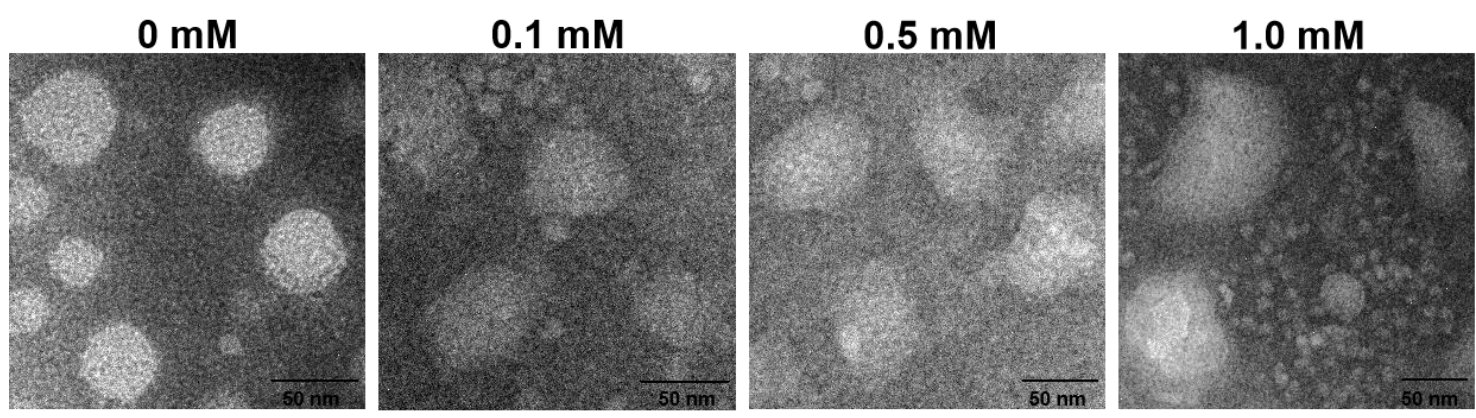

Figure S12. Morphology changes of DOX-loaded 1K-TPP micelles under different concentration of $\mathrm{H}_{2} \mathrm{O}_{2}$. The scale bar is $50 \mathrm{~nm}$. 


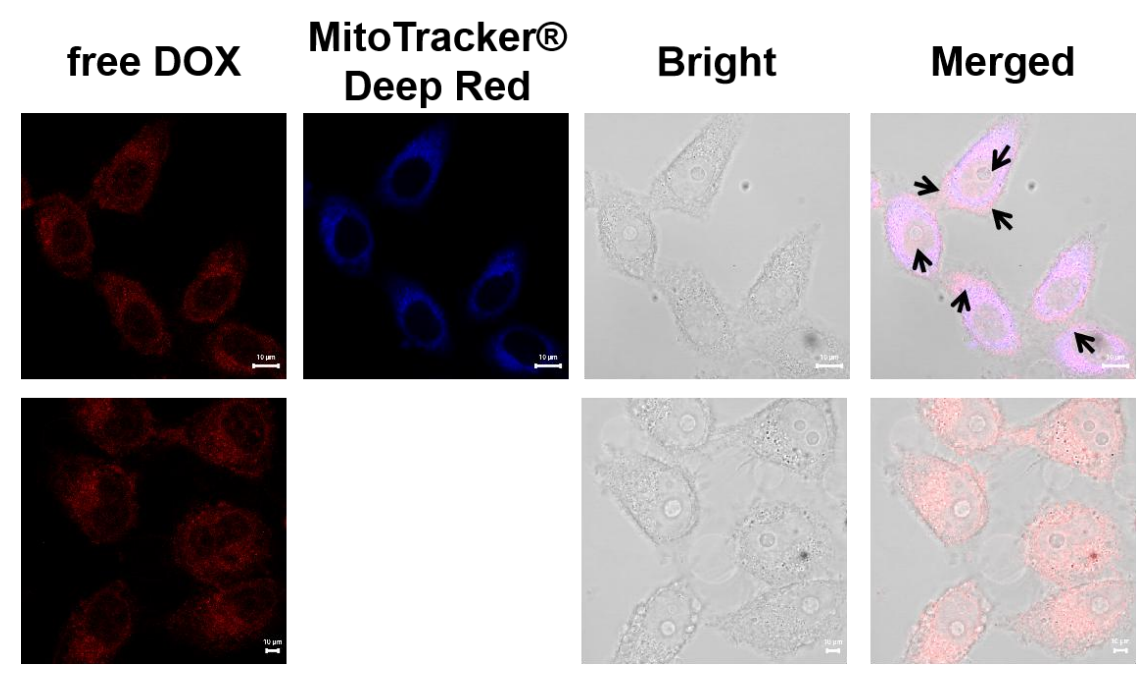

Figure S13. CLSM images of free DOX co-localization with or without MitoTracker ${ }^{\circledR}$ Deep Red for $4 \mathrm{~h}$.

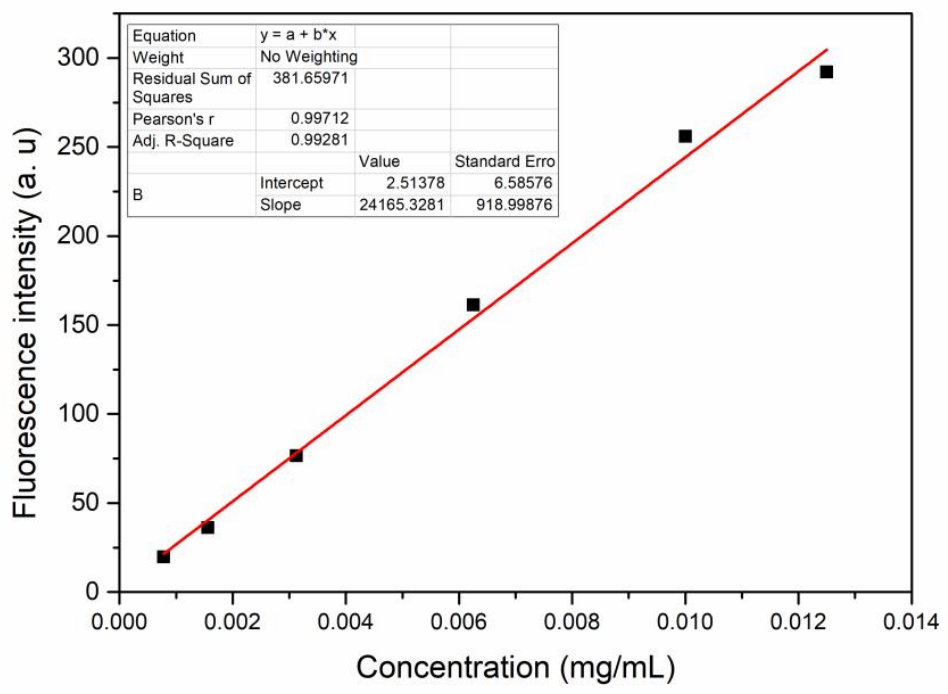

Figure S14. Standard curve of free DOX at $572 \mathrm{~nm}$ in DMF. 
(B)
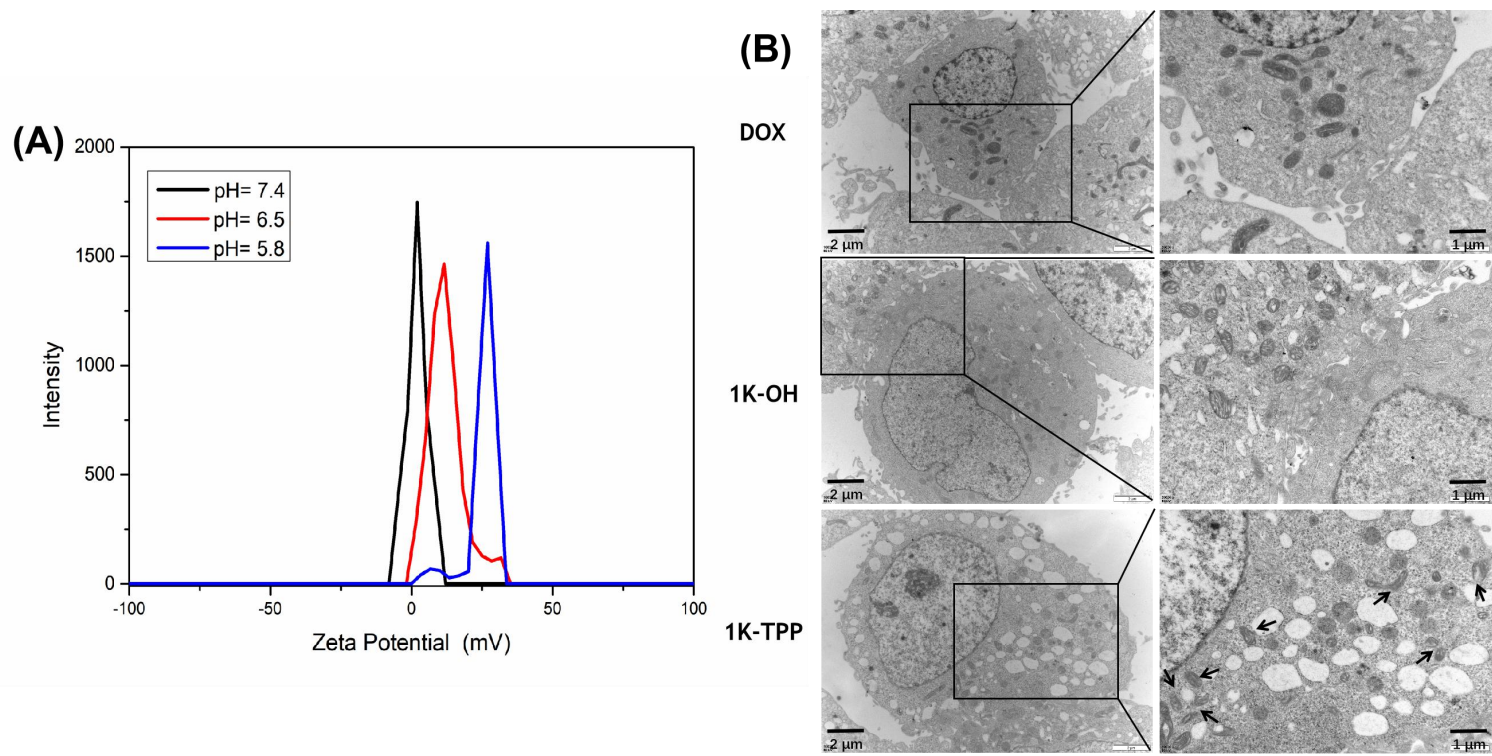

Figure S15. (A) Zeta potential of DOX-loaded 1K-TPP at different $\mathrm{pH}$ and (B)TEM images of cell mitochondria incubate with DOX, DOX-loaded 1K-OH and 1K-TPP after $4 \mathrm{~h}$.

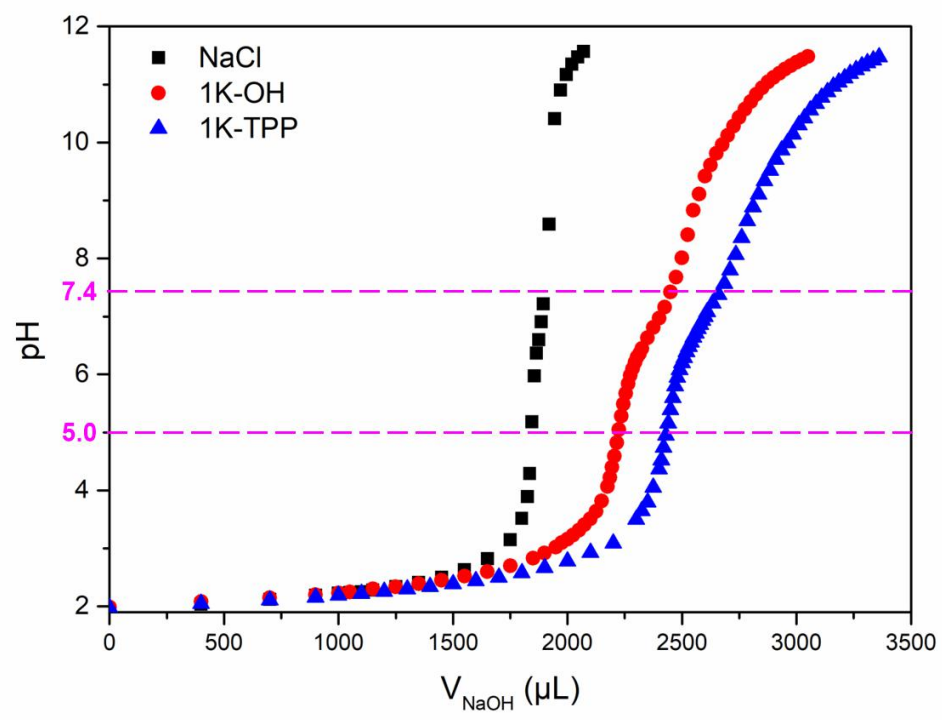

Figure S16. Acid-base titration of 1K-OH and 1K-TPP. 

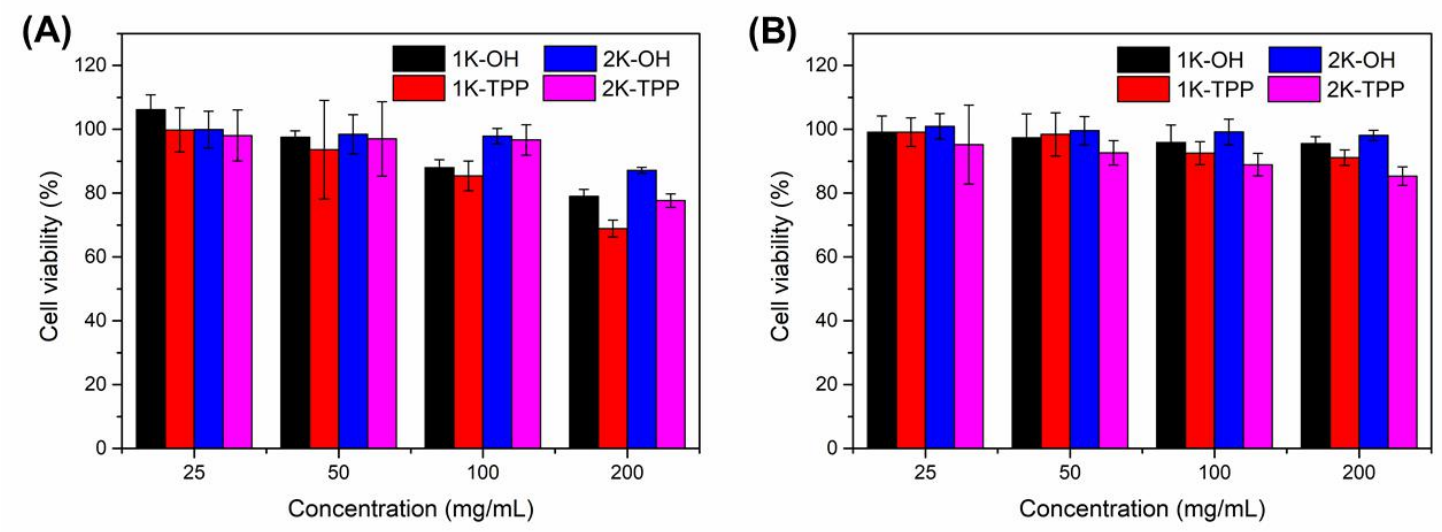

Figure S17. Cell cytotoxicity of (A) HeLa cells (B) HL-7702 cells incubating with blank 1K-OH, 1K-TPP, 2K-OH and 2K-TPP at different concentrations after $24 \mathrm{~h}$.

\section{References}

1. Liu, B. Y.; Wu, W. X.; Liu, Y. H.; Jia, C.; Yang, X. L.; Li, J.; Wang, N.; Yu, X. Q. Water-Soluble Mitochondria-Targeting Polymeric Prodrug Micelles for Fluorescence Monitoring and High Intracellular Anticancer Efficiency. Polym. Chem. 2017, 8, $5982-5987$.

2. Li, J.; Hu, Z. E.; Yang, X. L.; Wu, W. X.; Xing, X.; Gu, B.; Liu, Y. H.; Wang, N.; Yu, X. Q. GSH/pH Dual-Responsive Biodegradable Camptothecin Polymeric Prodrugs Combined with Doxorubicin for Synergistic Anticancer Efficiency. Biomater. Sci. 2019, 7, $3277-3286$.

3. Zhang, D.; Yang, Z. H.; Li, H. J.; Pei, Z. C.; Sun, S. G.; Xu, Y. Q. A Simple Excited-State Intramolecular Proton Transfer Probe Based on a New Strategy of Thiol-Azide Reaction for the Selective Sensing of Cysteine and Glutathione. Chem. Commun. 2016, 52, 749-752.

4. Li, J.; Yang, X. L.; Liu, Y. H.; Wu, W. X.; Liu, B. Y.; Wang, N.; Yu, X. Q. Chemoenzymatic Synthesis of Dual-Responsive Graft Copolymers for Drug Delivery: 
Long-Term Stability, High Loading and Cell Selectivity. J. Mater. Chem. B 2018, 6, 6993-7003. 